\title{
A positive patch test in an isoniazid-induced Dress syndrome
}

\section{Fatma Jendoubi, Kahena Jaber, Faten Rabhi, Mehdi Karray, Soumaya Youssef, Mohamed Raouf Dhaoui, Nejib Doss}

Department of Dermatology, Military Hospital of Tunis, Tunisia

Corresponding author: Dr. Fatma Jendoubi, E-mail: dr.jendoubi.fatma@gmail.com

Sir,

A 59-year old patient was diagnosed with severe psoriasis since 1989. He was treated with different therapies without any improvement. Therefore the decision was to start an anti-TNF theapy. Before initiating the treatment, latent tuberculosis was diagnosed with Mantoux test and quantiferon TB gold. The patient was treated by isonizaid $(450 \mathrm{mg} /$ day) and rifampicin $(600 \mathrm{mg} /$ day $)$. Three weeks later, he was hospitalized for a generalized cutaneous rash associated with an erythema and oedema of the face and hands and cheilitis. The patient had no fever and no lymphadenopathy. Laboratory evaluations showed a moderate increase in liver transaminases (aspartate aminotransferase $=85 \mathrm{U} / \mathrm{l})$ and eosinophilia $\left(1200 / \mathrm{mm}^{3}\right)$. The diagnosis of Drug Reaction with Eosinophilia and Systemic Symptom (DRESS) syndrome was made (RegiSCAR score $=3)$. Antituberculous treatment was discontinued and 15 days later, he was asymptomatic. Patch testing with rifampicin and isoniazid (each 30 and $20 \%$ ) was performed. Readings on day 2 showed a positive reaction only to isoniazid (Figs. 1 and 2).

Drug reaction with eosinophilia and systemic symptoms (DRESS) is a severe adverse drug-induced reaction. The syndrome includes a severe skin eruption, fever, hematologic abnormaltites (eosinophilia or atypical lymphocytes) and internal organ involvement. The other features are a delayed onset usually after 2-6 weeks after the initiation of drug therapy and a recovery over a period of two weeks of discontinuation of the culprit drug. Diagnostic criteria usually adopted are those of the international Registry of Severe Cutaneous

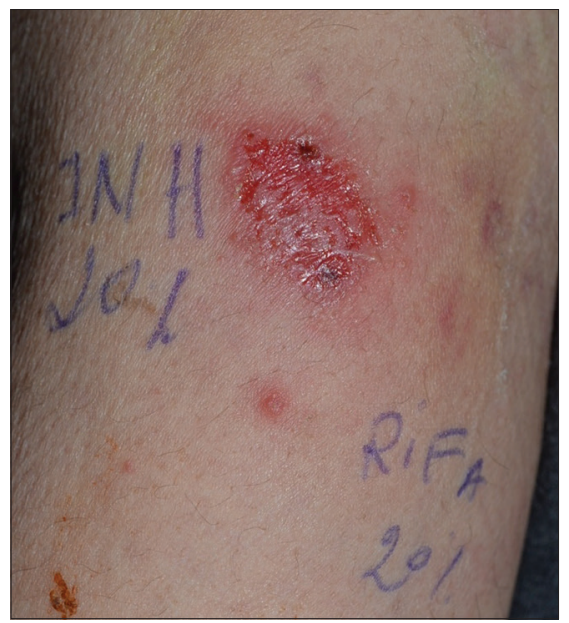

Figure 1: Positive patch test to isoniazid $20 \%$, negative to rifampicin.

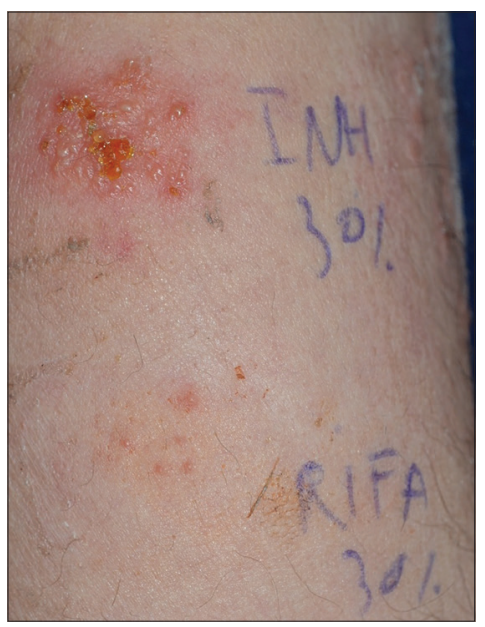

Figure 2: Positive patch test to isoniazid $30 \%$, negative to rifampicin.

Adverse Reactions group (RegiSCAR). The most often involved drugs are aromatic anti-epileptics (phenytoin, carbamazepine and phenobarbital) and allopurinol [1].

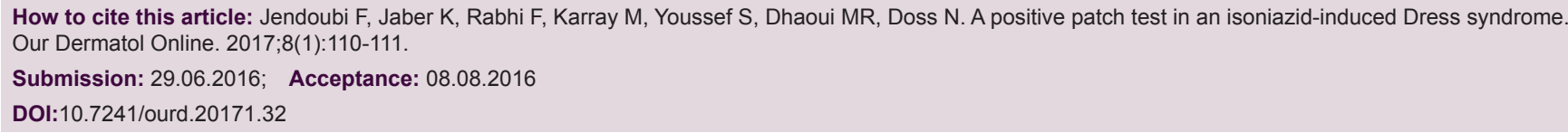




\section{www.odermatol.com}

Isoniazid is a very rare cause of DRESS [2-5]. The etiologic diagnosis is difficult as the result of the allergy workup is usually negative, and a challenge test is not advisable owing to potentially life-threatening consequences [3].

We present a case of isoniazid-induced DRESS in which the culprit agent was identified by positive patch test. Although the patch test was helpful in the diagnosis of DRESS, physicians should be aware of the possibility of life-threatening drug reactions associated with patch testing in DRESS [6].

\section{REFERENCES}

1. Cacoub P, Musette P, Descamps V, Meyer O, Speirs C, Finzi L, et al. The DRESS syndrome: a literature review. Am J Med. 2011;124:588-97.

2. Iwamoto S, Suzuki T, Sutani A, Kuraki T, Isobe T. [A case of atypical drug-induced hypersensitivity syndrome caused by isoniazid]. Kekkaku. 2012;87:777-82.

3. Arruti N, Villarreal O, Bernedo N, Audicana MT, Velasco M, Uriel O, et al. Positive Allergy Study (Intradermal, Patch, and Lymphocyte Transformation Tests) in a Case of Isoniazid-Induced DRESS. J Investig Allergol Clin Immunol. 2016;26:119-20.

4. Rubira N, Baltasar MA, Marti E. Hypersensitivity syndrome from isoniazid. Allergy. 1999;54:1011-2.

5. Ogawa K, Morito H, Kobayashi N, Fukumoto T, Asada H. Case of drug-induced hypersensitivity syndrome involving multiple-drug hypersensitivity. J Dermatol. 2012;39:945-6.

6. Shebe K, Ngwanya MR, Gantsho N, Lehloenya RJ. Severe recurrence of drug rash with eosinophilia and systemic symptoms syndrome secondary to rifampicin patch testing in a human immunodeficiency virus-infected man. Contact Dermatitis. 2014;70:125-7.

Copyright by Fatma Jendoubi, et al. This is an open access article distributed under the terms of the Creative Commons Attribution License, which permits unrestricted use, distribution, and reproduction in any medium, provided the original author and source are credited. Source of Support: Nil, Conflict of Interest: None declared. 